\title{
Computational Culture and A.I.: Challenging human identity and curatorial practice
}

\author{
Jonathan P. Bowen \\ London South Bank University \\ School of Engineering \\ London SE1 OAA, UK \\ http://www.jpbowen.com \\ jonathan.bowen@lsbu.ac.uk
}

Rachel Falconer

Goldsmiths, University of London

Goldsmiths Digital Studios

London, UK

http://rachelfalconer.co.uk

R.Falconer@gold.ac.uk

\author{
Tula Giannini \\ Pratt Institute \\ School of Information \\ New York, NY 10011, USA \\ http://sites.google.com/view/tgiannini \\ giannini@pratt.edu
}

Arthur I. Miller

University College London

Author, The Artist in the Machine

London, UK

http://www.arthurimiller.com

a.miller@ucl.ac.uk

\author{
Gareth Polmeer \\ Royal College of Art \\ Critical \& Historical Studies \\ London SW7 2EU, UK \\ http://www.garethpolmeer.com \\ gareth.polmeer@network.rca.ac.uk
}

\author{
Stuart Dunn \\ King's College London \\ Department of Digital Humanities \\ London, UK \\ http://www.kcl.ac.uk/people/stuart-dunn \\ stuart.dunn@kcl.ac.uk
}

\begin{abstract}
This half-day Symposium explores themes of computational culture and artificial intelligence (Al) in the context of digital art especially, as well as digital culture and heritage in general. The increasing ubiquity of $\mathrm{Al}$ and machine learning raises questions for technology and art in the future, and for the transformations that have already occurred concerning technology and the nature of being. Each symposium speaker approaches the issues from significantly different standpoints, illustrating the complex uncertain nature of the dynamics involved.
\end{abstract}

Computational culture. Al art. Digital aesthetics. Digital art. Digital culture. Digital heritage. Digitalism. Postdigital.

\section{INTRODUCTION}

This paper records a half-day Symposium of invited talks on the first day of the EVA London 2020 Conference. It continues a series from the previous four EVA London Symposiums held since 2016 (Bowen \& Giannini 2016; Bowen, Giannini \& Polmeer 2017; Bowen, Giannini, et al. 2018; 2019).

The Symposium series initially started in association with the Pratt Institute London Summer School, with an emphasis on digital culture and "digitalism" (Bowen \& Giannini 2014). A collaboration with the Royal College of Art developed, providing an artistic and philosophical angle to the Symposium (Polmeer 2016). Aspects of digital culture (Giannini \& Bowen 2018; 2019b) continue in this year's Symposium, which considers issues particularly concerning computational culture with respect to artificial intelligence (Al). The presenters for this 2020 Symposium come from a variety of backgrounds, including an artist, author, and academic.
The increasing ubiquity of artificial intelligence and machine learning raises a broad range of questions for the future of technology and art, and for the transformations that have taken place in the nature of being and technology (Polmeer 2019). In the field of artistic practice and exhibition, this has been increasingly engaged by a critically reflexive approach, seeking to question ideas around agency, autonomy, technology, identity, and the nature of creativity and meaning with newly emergent forms of networked practice. Collaborations between artists, curators, technology and exhibition contexts are variously interrelated, and these frame different ontological questions on the nature of the work of art, the nature of consciousness, identity and technology, and the reconceptualisation of creativity.

Each of the three symposium speakers approaches these questions from different perspectives, illuminating the complex and sometimes uncertain nature of these changing dynamics, and of how 
these alter and reframe contemporary and historical ideas of the artwork. The ideas emergent in new research practices examine the nature of the social, cultural, and political aspects of mind and technology, with the relation of past, present, and future, variously considered to understand human identity and curatorial practice. Speakers consider computational culture and Al exposing how this emerging phenomenon of everyday life is changing our ways of seeing, aesthetics, doing and being. As the conscious mind recedes into selfconsciousness, feeling uncertain about human identity, increasingly we experience a state of selfisolation and a growing tension between real and artificial life as computational life invades our ways thinking.

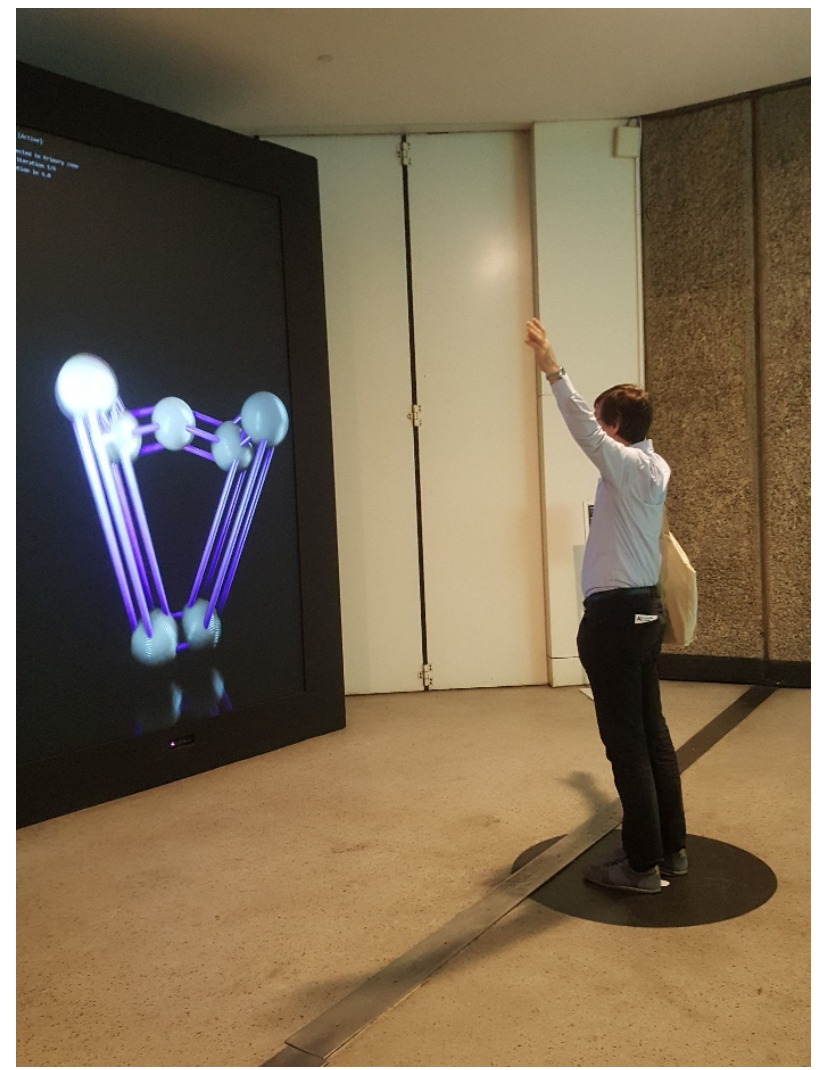

Figure 1: Jonathan Bowen interacting with Future You, Babican Exhibition, More Than Human, July 2019.

\section{COMPUTATIONAL CULTURE IN THE AGE OF ARTIFICIAL INTELLIGENCE}

Living in a postdigital world (Giannini \& Bowen 2019c), where humans and machines coexist in interdependent states of being, our understanding of what it means to be human is increasingly tested blurring the boundaries between real and artificial as we immerse ourselves in a new computational culture that is obsessed with $\mathrm{Al}$ and machine learning and how it can influence human behaviour and emotion, as if applying the Turing Test (Proudfoot 2017) to the nth degree - concluding that, yes, $\mathrm{Al}$ is "more than human". With the latest advances in $\mathrm{Al}$ and machine learning introduced by the winners of the 2018 ACM A.M. Turing Award, Yoshua Bengio, Geoffrey Hinton, and Yann LeCun (ACM 2018), computers can now feign human-like senses: seeing, visual recognition, hearing, touch and natural language searching. In the context of computational culture, will Al senses compete with human sensibilities? Enter the digital assistants, avatars and robots like Alexa, or the newly designed "digital employee" Amelia. (IPsoft 2020).

The 2019 exhibition at the Barbican in London, Al: More Than Human, explores in depth how Al challenges our notions of human and artificial life (Giannini \& Bowen 2017), from the start to finish of the visitor experience. Upon entering the building and heading to exhibition itself, the visitor was immersed in an interactive digital display commissioned by the Barbican and created by Universal Everything (see Figure 1), posing the question (Universal Everything 2019):

\begin{abstract}
"How do you feel when you see a synthetic version of yourself?"

In Future You, you are faced with a unique reflection of your potential, synthetic self. Starting as a primitive form, it learns from your movements to adapt, suggesting an agile, superior version of you. This artwork evolves, creating a new visual response for each visitor, generating 47,000 possible variations."
\end{abstract}

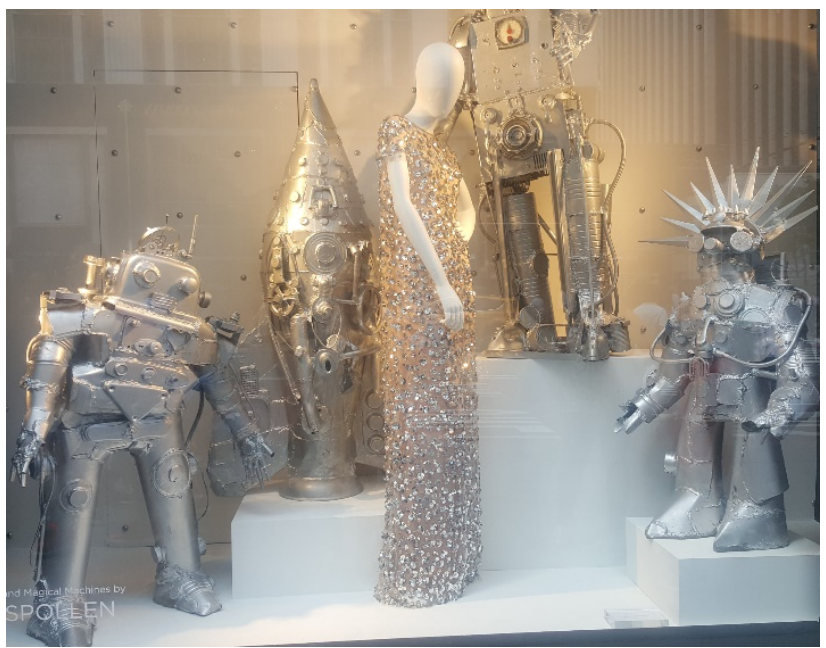

Figure 2: Window display, Bergdorf Goodman, 5th Ave. New York City. Robots by Chris Spollen (2019).

(Photograph by T. Giannini, August 2019.)

After experiencing the exhibition, visitors find themselves asking, has human identity assumed a more robotic state (see Figure 2), as humans seek to accommodate the rise of computational culture causing the being of human beings to become less than human. Are we not counting on what we have always considered to be uniquely human - our creativity, innovation, intuition, instincts and common sense? Ironically, the coronavirus crisis 
has pushed everyday life further into the digital realm, impacting most aspects of human activity, from education: no more face to face teaching communication: it is all email and Twitter - to shopping on Amazon and virtual reality museums.

As a leading curator of art and technology, Rachel Falconer's work shows how the curatorial role is transforming as new Al tools can see and analyze collections and serve to intermediate exhibitions. For example, MoMA is collaborating with the Google Arts and Culture Lab to use Al for selecting art works from their collections for public exhibitions, and the Metropolitan Museum is working with Microsoft and MIT to use Al to help users search the Met's collections database in meaningful ways. Both projects are creating intelligent systems to "curate" database images. (Choi 2019; Lih 2019). As computational systems develop more sophisticated neural networks that emulate the human brain, such as seeing and identifying relationships between images and applying metadata, curators will focus more on the human tasks of interpretation, design and aesthetics, so that a highly creative and innovative curator like Falconer can focus on "curating" meaning and message, interactive and participatory exhibitions that are relevant to contemporary art and life.

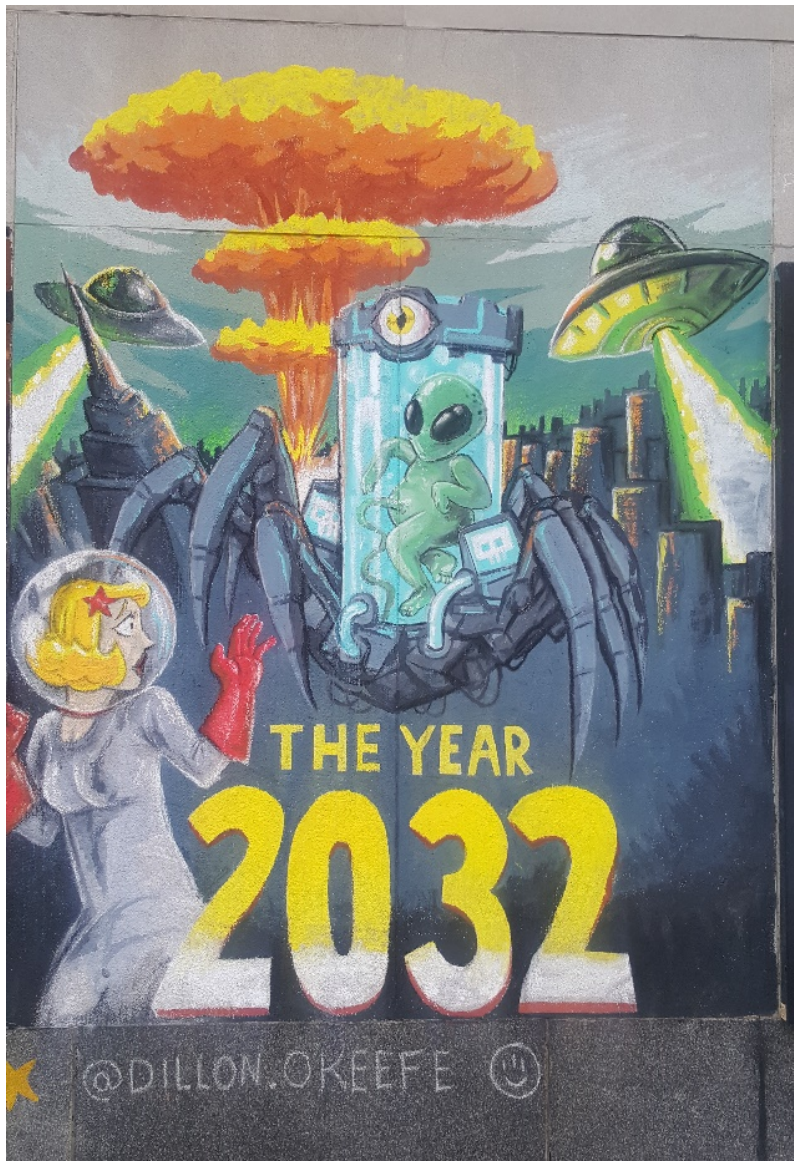

Figure 3: Chalk-it mural by Dillon O'Keefe, a senior at Fashion Institute of Technology in New York City, 2020.
The chalk mural (Figure 3 ) seems to show humans succumbing to the reign of non-human Al beings as a dominant force that reinvents human experience in a 2032 apocalyptic moment. Arthur Miller poses questions about how human identity and art will be transformed in the age of $\mathrm{Al}$ - questions that are front and center for us humans living in a computational culture. Although individuals will have varied responses, the pace of technological advances to simulate human-like beings capable of doing a wide range of jobs that once seemed exclusively human changes the human-machine equation. Miller brings new insights and vision to this and identifies other challenges as we increasingly compare human and $\mathrm{Al}$ art and aesthetics, and surmises that Al making art might be better than humans, and this notion speaks to the theme of the Barbican exhibition - Al more than human.

Stuart Dunn delves into how human insight and subject expertise are being recognised in digital humanities and digital art history as being central to collection analysis using linked open data and visualisation on the macro and micro levels. The British Museum's ResearchSpace with funding from the Melon Foundation identities the problems with data saying (ResearchSpace 2019):

\begin{abstract}
"The idea that simply opening up data which has been designed with the continued mindset of closed design and standards governed by database modellers rather than subject experts will somehow be transformed into hugely valuable knowledge when released into the open, and linked, is incorrect."
\end{abstract}

This suggests the need for real relationships between human and artificial intelligence and thinking. As Alan Turing intimated with his "universal computing machine" (Copeland 2017), machines are better at computing - no competition - we question what humans do best.

\section{PROGRAMME}

\section{Rachel Falconer, Goldsmiths Digital Studios}

\section{Title: Leaky Box Scenarios: Curating in the context of "creative" Al}

Curating digital and network-based art has a long and well-rehearsed history, chequered by institutional and counter-institutional tensions. As a result, a more interventionist set of curatorial practices and strategies have emerged when approaching the modes and technologies of display of digital art which reach far beyond the conventions of the white cube. Furthermore, with the increasingly popular implementation of creative 
Al systems across both artistic practice and the creative industries, how is the role of the curator beginning to morph from panoptic aggregator to a more distributed set of power relations? In this talk I set out a number of provocations around the strategies and politics of distributed curatorial practice, the perceived creative autonomy of creative $\mathrm{Al}$ and question the binary approach to the relationship between human agency and machinic servitude. Taking a techno feminist approach to foregrounding the agency of non-human entities across curatorial practices, this talk challenges our positioning towards the opacity of $\mathrm{Al}$ and questions where the curator must place herself (or selves) in order to open up a more distributed curatorial attitude.

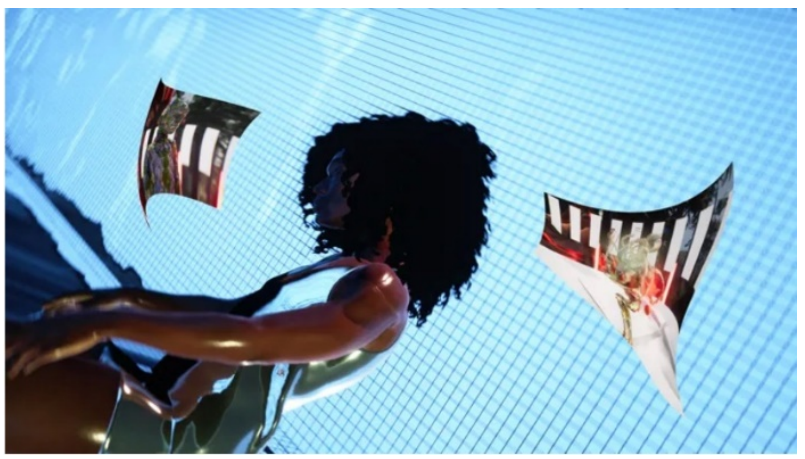

Figure 4: Keiken \& George Jasper Stone: Feel My Metaverse, 2019. Created for Jerwood Collaborate! Supported by Jerwood Arts.

Biography

Rachel Falconer is a digital art curator, researcher and lecturer in Digital Arts Computing and Creative Computing. She also heads up the creative technology prototyping and research initiative Goldsmiths Digital. As an independent curator, researcher and development consultant she operates at the critical intersections of contemporary art practice, emergent technologies, civic data infrastructures and networked culture. Drawing on her international experience in the film, advertising and gaming industries to inform her systems-based practice, Rachel has conceived and delivered multi-scale interdisciplinary public programming, alternative exhibition models and innovative public research platforms spanning a diversity of industries and critical modes of engagement with technology.

Rachel is regularly invited to speak at public events and has participated in public programmes at institutions including: Tate, Barbican, V\&A, Royal College of Art, The Lumen Prize, Rhizome, London Design Festival, The Institute of Network Cultures (Amsterdam), Fabrikken (Copenhagen), and Furtherfield, and her research and writing has been published across a wide range of platforms including The Guardian, British Journal of Photography, Dazed Digital and The White Review.
She is a contributing author to academic publications. Most recently her chapter on distributed digital knowledge production was included in Radical Cut-Up, Nothing is Original, edited by Lucas Feireiss (2019).

\section{Arthur I. Miller, University College London}

\section{Title: The World of Al-Powered Creativity}

Today machines are already showing glimpses of creativity. As Al develops, completely new forms of art, literature and music, currently unimaginable, are bound to emerge. I explore this amazing new world, looking into questions like the following. Can computers be really creative? Will we need to rethink concepts like 'art' and 'creativity' and, if so, how? Will these developments lead to a better understanding of how Als themselves work - that is to say, think? Will we be able to develop machines that have consciousness? How will human identity be transformed in the age of Al. I examine this and much, much more.

For details, see the extensive bibliography in The Artist in the Machine (Miller 2019).

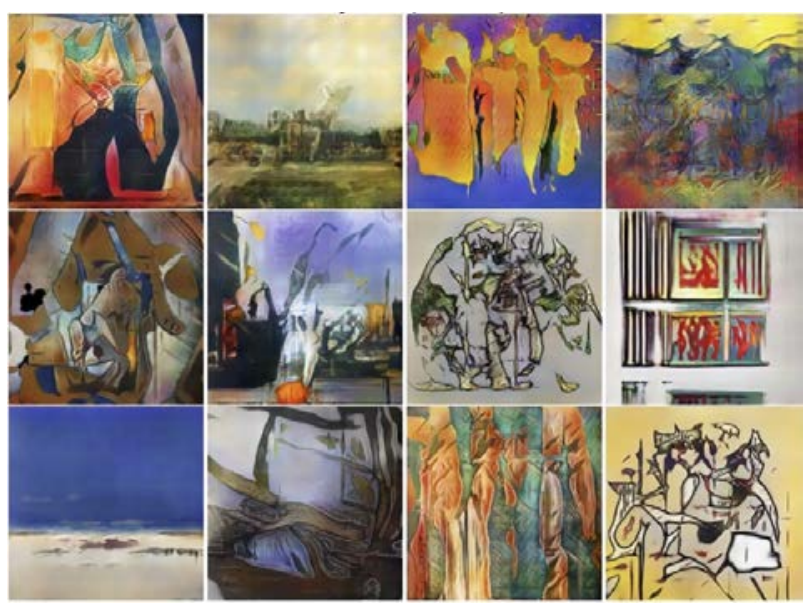

Figure 5: An example of the styles created by Ahmed Elgammal's Creative Adversarial Network (CAN). (Courtesy of Ahmed Elgammal.)

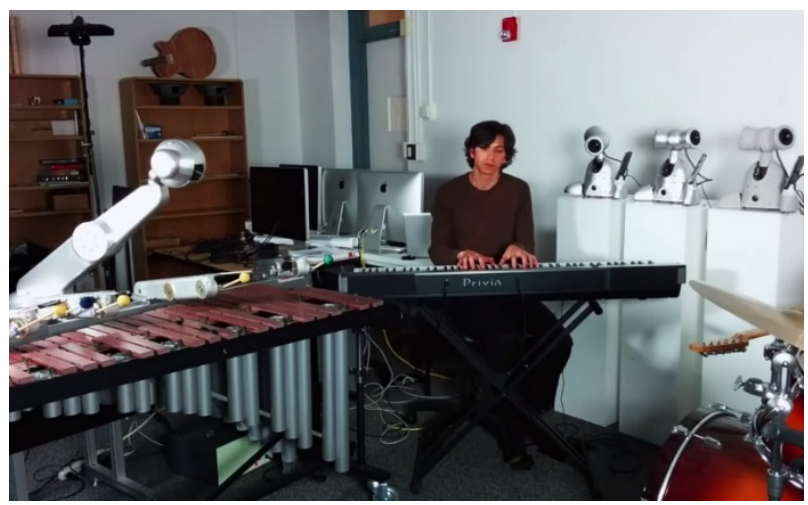

Figure 6: Mason Bretan and robots improvising jazz. Each robot on Bretan's right is called Shimi 
and the one on his left is Shimon.

(Courtesy of Mason Bretan.)

\section{Biography}

Arthur I. Miller is fascinated by the nature of creative thinking. He has published many critically acclaimed books, including Insights of Genius; Einstein, Picasso (shortlisted for a Pulitzer); Empire of the Stars (shortlisted for the Aventis Prize); and 137, and writes for The Guardian, The New York Times, and Wired. He is professor emeritus of history and philosophy of science at University College London. An experienced broadcaster and lecturer, he has judged art competitions and curated exhibitions on art/science. His previous book, Colliding Worlds, tells the story of how art, science and technology are fusing in the twentyfirst century. The Artist in the Machine: The World of Al-Powered Creativity is based on the hundredodd interviews he did with scientists on the cuttingedge of Al-created art, literature and music. It celebrates the creative possibilities of $\mathrm{Al}$ in the arts.

\section{Stuart Dunn, King's College London}

\section{Title: Networks of Objects or Objects as Networks? Rethinking digital art history (again)}

Much attention has been given to the use of network analysis to identify patterns and trends in artistic and cultural collections and their audience (Coffee 2007). This has been driven by key initiatives in the spheres of Digital Art History (Bishop 2018; Drucker 2013), Linked Open Data (Davis 2019), and the digitisation of catalogues of art collections. In turn, many such initiatives have their origins in (or even as) solutions to the curatorial need to link and manage collections. Because of this, the idea that a digital object (Dunn et al. 2019) such as a Uniform Resource Indicator (URI) must relate to an object (Gosden \& Marshall 1999), or physical attributes of an object, in the same way that (for example) a photograph does, has gained currency. Drawing on two projects with which the speaker has been involved, Ancient Itineraries: The Digital Lives of Art Objects and Network Analysis and Digital Art History, both funded by the Getty Foundation, I seek to reverse this assumption. Drawing on current theories and practices of networks in digital art history, I examine how objects can, themselves, be presented as networks of influence, connoisseurship, styles, ideas, and even people; and thus provide new perspectives on what the idea of the network can bring to art history.

\section{Biography}

Stuart Dunn is Senior Lecturer in Digital Humanities at King's College London. He started out as an archaeologist, with interests in the history of cartography, digital approaches to landscape studies, and spatial humanities. He has been a visiting scholar at Stanford University's Center for Electronic Spatial and Textual Analysis, and the Australian National University's Centre for Digital Humanities. He currently works on projects in spatial narrative theory, critical GIS, Cypriot cultural heritage, and the archaeology of mobility. Stuart gained an interdisciplinary PhD on Aegean Bronze Age dating methods and palaeovolcanology from the University of Durham in 2002, conducting fieldwork in Melos, Crete, and Santorini.

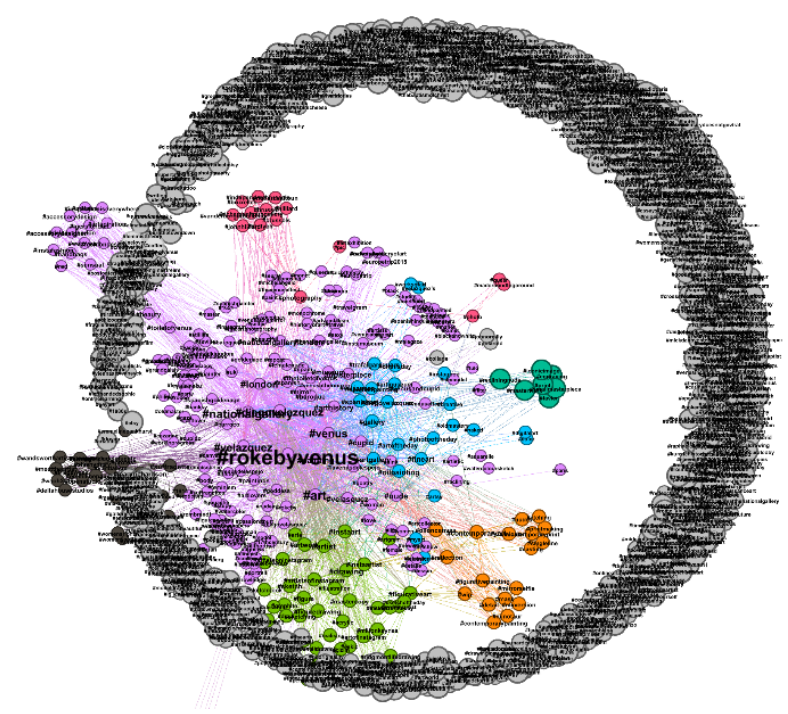

Figure 7: Network graph showing the sphere of influence of the Rokeby Venus. (Image by Valentina Vavassori, reproduced with permission.)

\section{CONCLUSION}

Human identity and art in the emerging world of $\mathrm{Al}$ and machine learning at once promises great scientific advancement while on a personal level many humans are fearful of losing their place and purpose in society. How much can we alter our human identity before it becomes less than human and more artificial. As digital time dominates our engagement, with the average person spending 10-12 hours per day online, digital life begins to seem more authentic than real life (Bowen \& Giannini 2014; Giannini \& Bowen 2016; 2017), while real life fades from our memory - was real life ever real - did it even exist?

\section{Can't Really Remember by T. Giannini}

I can't remember your touch

How tall are you?

Did we meet on the Web?

Are you real?

You look like a robot I once knew

I can't hear your voice

It seems far away

Are you calling from another planet I'm no longer real - 
Just an avatar

My Al is failing

I'm failing fast

Our relationship can't last

The Symposium talks have been designed to cover a range of issues in computational culture and artificial intelligence, in the context of art, culture, and heritage. A bibliography of related publications by the Symposium chairs and speakers is included below for further reading.

Online information concerning the EVA London 2020 Symposium is available under:

http://www.eva-london.org/eva-london2020/symposium/

\section{Acknowledgements}

The EVA London 2020 Symposium was supported as part of the EVA London 2020 Conference. Jonathan Bowen is grateful to Museophile Limited for financial support.

\section{BIBLIOGRAPHY}

ACM (2018) Fathers of the Deep Learning Revolution Receive ACM A.M. Turing Award. Association for Computing Machinery. URL: https://awards.acm.org/about/2018-turing

Bishop, C. (2018) Against digital art history. International Journal for Digital Art History, 3. DOI: 10.11588/DAH.2018.3.49915

Bowen, J. P., Diprose, G., and Lambert, N. (eds.) (2016) EVA London 2016: Electronic Visualisation and the Arts. BCS, Electronic Workshops in Computing. ScienceOpen. DOI:

10.14236/ewic/EVA2016.0

Bowen, J. P., Diprose, G., and Lambert, N. (eds.) (2017) EVA London 2017: Electronic Visualisation and the Arts. BCS, Electronic Workshops in Computing. ScienceOpen. DOI:

10.14236/ewic/EVA2017.0

Bowen, J. P. and Giannini, T. (2014) Digitalism: The new realism? In $\mathrm{K}$. Ng, J. P. Bowen, and $\mathrm{S}$. McDaid (eds.), EVA London 2014: Electronic Visualisation and the Arts. BCS, Electronic Workshops in Computing, pp. 324-331. DOI:

10.14236/ewic/eva2014.38

Bowen, J. P. and Giannini, T. (2016) From analogue to digital in literature and art. In Bowen et al. (2016), pp. 1-4. DOI: 10.14236/ewic/EVA2016.1

Bowen, J. P., Giannini, T., Ara, R., Lomas, A., and Siefring, J. (2019) States of Begin: Art and identity in digital space and time. In Weinel et al. (2019), pp. 1-9. DOI: 10.14236/ewic/EVA2019.1
Bowen, J. P., Giannini, T., and Polmeer, G. (2017) Coded communication: Digital senses and aesthetics, merging art and life. In Bowen et al. (2017), pp. 1-8. DOI: 10.14236/ewic/EVA2017.1

Bowen, J. P., Giannini, T., Polmeer, G., Gannis, C., Gardiner, J., Kearney, J., Wands, B., and Weinel, J. (2018) States of Begin: Art and identity in digital space and time. In Bowen et al. (2018c), pp. 1-7. DOI: 10.14236/ewic/EVA2018.1

Bowen, J. P., Weinel, J., Diprose, G., and Lambert, N. (eds.) (2018) EVA London 2018: Electronic Visualisation and the Arts. BCS, Electronic Workshops in Computing. ScienceOpen. DOI: 10.14236/ewic/EVA2018.0

Choi, J. (2019) Exploring Art with Open Access and Al: What's Next? Metropolitan Museum, Blogs, 11 June. URL: https://www.metmuseum.org/blogs/ now-at-the-met/2019/met-microsoft-mit-exploringart-open-access-ai-whats-next

Coffee, K. (2007) Audience research and the museum experience as social practice. Museum Management and Curatorship, 22(4), pp. 377-389. DOI: $10.1080 / 09647770701757732$

Copeland, B. J. (2017) Turing's great invention: The universal computing machine. In B. J. Copeland et al. (2017), chapter 6, pp. 49-56.

Copeland, B. J., Bowen, J. P., Sprevak, M. and Wilson, R. (eds.) (2017) The Turing Guide. Oxford University Press.

Davis, K. (2019) Old metadata in a new world: Standardizing the Getty Provenance Index for linked data. Art Libraries Journal, 44(4), pp. 162166. DOI: $10.1017 /$ alj.2019.24

Drucker, J. (2013). Is there a "digital" art history? Visual Resources, 29(1-2), pp. 5-13. DOI: 10.1080/01973762.2013.761106

Dunn, S. Earl, G., Foka, A., and Wootton, W. (2019) Spatial narratives in museums and online: The birth of the digital object itinerary. In Giannini \& Bowen (eds.) (2019a), chapter 12, pp. 253-271. DOI: 10.1007/978-3-319-97457-6 12

Feireiss, L. (ed.) (2019) Radical Cut-Up, Nothing is Original. Sternberg Press. URL:

https://www.studiolukasfeireiss.com/Radical-CutUp-Nothing-is-Original

Giannini, T. and Bowen, J. P. (2016) Curating digital life and culture: Art and information. In Bowen et al. (2016), pp. 237-244. DOI:

10.14236/ewic/EVA2016.46

Giannini, T. and Bowen, J. P. (2017) Life in code and digits: When Shannon met Turing. In Bowen et al. (2017), pp. 51-58. DOI: 10.14236/ewic/EVA2017.9 
Giannini, T. and Bowen, J. P. (2018) Of museums and digital culture: A landscape view. In Bowen et al. (2018), pp. 172-179. DOI:

10.14236/ewic/EVA2018.34

Giannini, T. and Bowen, J. P. (eds.) (2019a) Museums and Digital Culture: New Perspectives and Research. Springer, Series on Cultural Computing. DOI: 10.1007/978-3-319-97457-6

Giannini, T. and Bowen, J. P. (2019b) Digital culture. In Giannini \& Bowen (eds.) (2019a), chapter 1, pp. 3-26. DOI: 10.1007/978-3-31997457-6 1

Giannini, T. and Bowen, J. P. (2019c) Art and Activism at museums in a post-digital world. In Weinel et al. (2019), pp. 27-35. DOI: 10.14236/ewic/EVA2019.4

Gosden, C. and Marshall, Y. (1999) The cultural biography of objects. World Archaeology, 31(2), pp. 169-178. DOI: $10.1080 / 00438243.1999 .9980439$

Miller, A. I. (2019) The Artist in the Machine: The World of Al-Powered Creativity. The MIT Press. URL: http://www.artistinthemachine.net

IPsoft (2020) Digital Workforce.ai by Amelia: The World's First Marketplace for Digital Employees. URL: https://www.ipsoft.com/digitalworkforce/

Lih, A. (2019) Combining Al and Human Judgment to Build Knowledge about Art on a Global Scale. Metropolitan Museum, Blogs, 4 March. URL: https://www.metmuseum.org/blogs/now-at-themet/2019/wikipedia-art-and-ai
MoMA (2020) Identifying art through machine learning: A project with Google Arts \& Culture Lab. The Museum of Modern Art. URL:

https://www.moma.org/calendar/exhibitions/history/i dentifying-art MoMA

Polmeer, G. (2016) Sublating time: Hegel's speculative philosophy and digital aesthetics. In Bowen et al. (2016), pp. 257-264. DOI:

10.14236/ewic/EVA2016.49

Polmeer, G. (2019) Historical questions on being and digital culture. In Giannini \& Bowen (eds.) (2019a), chapter 3, pp. 49-62. DOI: 10.1007/978-3319-97457-6 3

Proudfoot, D. (2017) The Turing Test - fromm every angle. In B. J. Copeland et al. (2017), chapter 27, pp. 287-300.

ResearchSpace (2019) Presentation Script - Why Linked Data for Conservation? British Museum. URL: https://www.researchspace.org/conservation science.html

Spollen, C. (2019) The Show. Drawger.com, 12 August. URL:

https://www.drawger.com/spollen/articles/16042

Universal Everything (2019) Barbican, Future You: An interactive reflection of your future self, London. URL: $\quad$ https://universaleverything.com/projects/ future-you

Weinel, J., Bowen, J. P., Diprose, G., and Lambert, N. (eds.) (2019) EVA London 2019: Electronic Visualisation and the Arts. BCS, Electronic Workshops in Computing. ScienceOpen. DOI: 10.14236/ewic/EVA2019.0 